\title{
Fire retardancy and environmental assessment of rubbery blends of recycled polymers
}

\author{
Sz. Matkó, I. Répási, A. Szabó, B. Bodzay, P. Anna, Gy. Marosi* \\ Budapest University of Technology and Economics, Department of Organic Chemistry and Technology, Budafoki út 8., \\ H-1111 Budapest, Hungary
}

Received 24 October 2007; accepted in revised form 3 January 2008

\begin{abstract}
Flame retarded thermoplastic polymer compounds were prepared containing recycled rubber tyres, low density polyethylene, ethylene vinyl acetate copolymer and an intumescent additive system consisting of waste polyurethane foam and ammonium polyphosphate. The effect of the additives on the combustion properties was characterised by Limiting Oxygen Index, UL 94 and mass loss calorimetric measurements. The environmental impact was estimated by determining the gas components of $\mathrm{CO}_{2}$ and $\mathrm{CO}$ evolving from the compounds during the burning process using a gas analyser system constructed by coupling an FTIR unit to a mass loss calorimeter. The new material forms a thermoplastic rubber of excellent processability making it suitable for application in construction industry.
\end{abstract}

Keywords: recycling, rubber waste, intumescent flame retardant, evolved gas analysis, polyurethane

\section{Introduction}

There are over 2.5 million tonnes of waste tyres arising in Europe each year. This high amount initiated the commencement of the 2000/53/EC directive of the European Parliament and of the Council [1], which prescribes the recovery, reuse and recycling of the end-of life vehicles including rubber tyres. Since July 2006, waste tyres have been totally banned from landfills.

Utilizing options of waste rubber vulcanizates are incineration, pyrolysis [2, 3], gasification [4-6], devulcanization (e.g. chemical [7], mechanochemical $[8,9]$, supercritical $[10,11]$, ultrasonic $[12$, 13]), or blending either in thermoset [14-16] or in thermoplastic [17-19] polymer matrices. In this work we selected the last mentioned option combining it with upgrading that is to transform the rubber waste containing compound to a special flame retardant material.
There are known many ways to obtain flame retardant rubbers (synthetic or natural) or rubber containing composites by incorporation of flame retardant additive. E.g. ammonium polyphosphate/ aluminium trihydroxide system [20], ammonium polyphosphate [21], ethylene-diamine phosphate [21] or nanoparticles (e.g. nanoclays [22], nanocalcium sulphate [23], nano-magnesium hydroxide [24-26]) are suitable flame retardants.

In our work we used ammonium polyphosphate/ polyurethane intumescent additive system. This system proved to be an effective flame retardant in ethylene propylene rubber [27], polypropylene [28] and ethylene vinyl acetate copolymer matrices [29, 30]. Bugajny et al. pointed out that the chemical reaction taking place between ammonium polyphosphate and thermoplastic polyurethane leads to the formation of an intumescent shield and provides improved thermal stability for the material [31].

*Corresponding author, e-mail: gmarosi@mail.bme.hu

(C) BME-PT and GTE 
Carbon dioxide/carbon monoxide yield ratio and toxicity of fires can be evaluated from small scale tests such as cone calorimeter or tube furnace (Purser furnace) methods [32, 33]. However the results obtained from these tests may differ because of the varying test conditions (e.g. vitiated combustion, rapid quenching of the fire gases, less- or wellventilated conditions etc).

This work focuses on the flame retardant effect of APP/PU intumescent additive system in LDPE/ EVA based polymer matrix containing rubber waste, and on the environmental effect of the additive by analysing the evolved gases during combustion. The flammability was tested by LOI, UL 94 and mass loss calorimeter and the gas analysis was performed by FTIR attached in line to the mass loss calorimeter.

\section{Experimental}

\subsection{Materials}

Low density polyethylene (LDPE): Tipolen AE 2016 (TVK Rt. Hungary). Ethylene vinyl acetate copolymer (EVA): Ibucell K-100 (H. B. Fuller, Germany). Recycled rubber $(R U B)$ : the $200-600 \mu \mathrm{m}$ fraction of a rubber powder prepared by an ultra high pressure water jet cutting process [34] (Regum Kft. Hungary). Ammonium polyphosphate (APP): Exolit AP 422
(Clariant Ltd. Germany). Recycled polyurethane foam $(P U)$ : ground, freon free waste polyurethane foam recovered from fridges (Amatech-Polycel Inc. Germany). Glycerol monostearate (GMS): commercial product (Chemiplast Kft. Hungary).

\subsection{Preparation of samples}

Compounding: the components were homogenised in a Brabender Plasti Corder PL 2000 apparatus, at $150^{\circ} \mathrm{C}$, with a rotor speed of $50 \mathrm{rpm}$, for $10 \mathrm{~min}$. Test sheets: the blends were compressed in a Collin P 200 E laboratory compression moulding machine at $150^{\circ} \mathrm{C}$, with $10 \mathrm{bar}$, for $10 \mathrm{~min}$.

\subsection{Methods of evaluation}

UL 94 flammability and Limiting Oxygen Index (LOI) according to the standards [35, 36]. Mass loss calorimetry with heat flux of $50 \mathrm{~kW}$ (this value corresponds to the heat generated in a well-developed fire [38]), without direct ignition according to the standard [37]. Infrared gas analysis (FTIR): the gas evolving from the samples being exposed to $50 \mathrm{~kW} / \mathrm{m}^{2}$ radiation in the mass loss calorimeter was analysed by a Bruker Tensor 37 FTIR. The mass loss calorimeter was connected (at atmospheric pressure) with the infrared spectrometer according to Figure 1, by interface elements con-

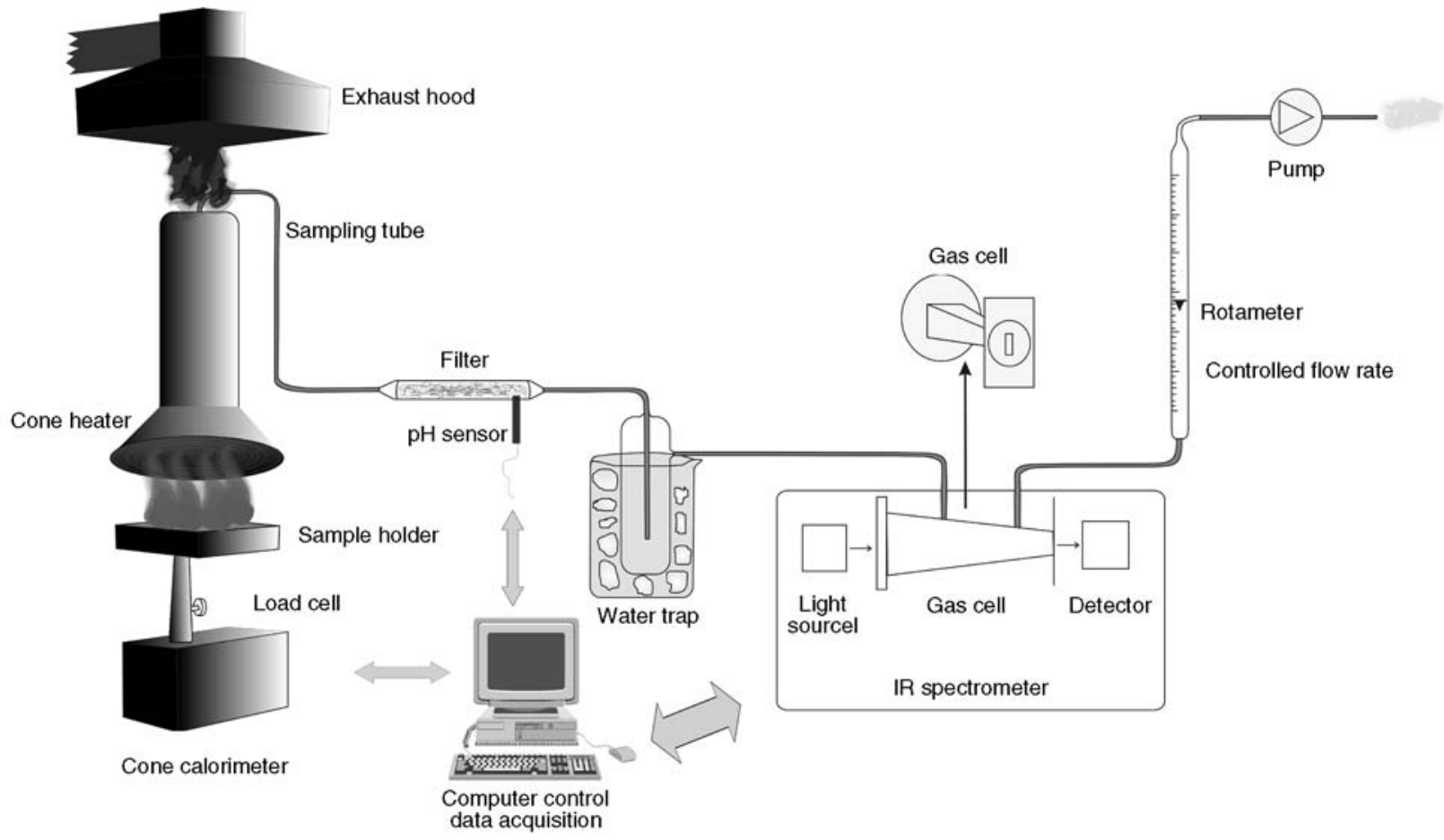

Figure 1. Scheme of gas analyzer consisting of the mass loss calorimeter, FTIR spectrometer and interface elements 
sisting of glass sampling tube, glass-wool filled filter and condenser, in order to detect the evolved gases. The pathlength of the single pass gas cell was $100 \mathrm{~mm}$ made of stainless steel. As the gas cell contains a $\mathrm{NaCl}$ window, which is sensitive to water, the evolved water vapour was condensed in a trap cooled by the mixture of water and ice. The spectra recorded throughout the test were evaluated by Opus 5.5 software in the range of 650$4000 \mathrm{~cm}^{-1}$. Among the toxic products we focused on $\mathrm{CO}$ and $\mathrm{CO}_{2}$ with characteristic bands at (2171 and $\left.2118 \mathrm{~cm}^{-1}\right)$ and $\left(2363,2341\right.$ and $\left.2336 \mathrm{~cm}^{-1}\right)$ and identified by using Reference [39].

Mechanical properties: tensile properties (tensile strength, relative elongation at break and tensile modulus) were measured according to the standard [40] by a Zwick Z020 testing machine. The measurements were evaluated by TestXpert V10.11 software.

\section{Results and discussion}

\subsection{Flammability}

The compositions of the Reference, of the compounds containing APP/PU intumescent additive system (Samples 1-3) and of the compound con-

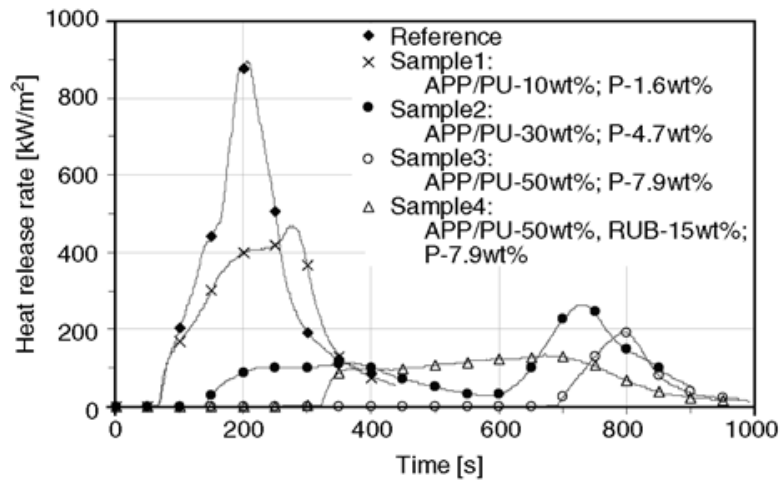

Figure 2. Heat release rate (HRR) vs. Time in mass loss calorimetric measurement of the compounds

taining APP/PU/RUB additive system (Sample 4) are given in Table 1. The APP/PU weight ratio was $1 / 1$ in all cases. The LDPE/EVA weight ratio was also constant in all samples. Table 1 contains also the results of UL 94 and LOI flammability tests and the characteristic values could be evaluated from the Heat release rate (Figure 2) and Mass loss curves (Figure 3 ) of mass loss calorimetric measurements.

Comparing the characteristics of Reference and Sample 1, it can be seen that phosphorus content of $1.6 \mathrm{wt} \%$ does not lead to improvement in either UL 94 grade, LOI or $t_{i g n}$. Both Reference and Sam-

Table 1. Composition in wt $\%$ and flame-retardant characteristics of Reference and Sample 1, 2, 3 and 4

\begin{tabular}{|c|c|c|c|c|c|}
\hline Components & Reference & 1 & 2 & 3 & 4 \\
\hline LDPE & 26.6 & 23.9 & 18.5 & 13.1 & 9.1 \\
\hline EVA & 72.4 & 65.1 & 50.5 & 35.9 & 24.9 \\
\hline APP & - & 5.0 & 15.0 & 25.0 & 25.0 \\
\hline PU & - & 5.0 & 15.0 & 25.0 & 25.0 \\
\hline RUB & - & - & - & - & 15.0 \\
\hline GMS & 1.0 & 1.0 & 1.0 & 1.0 & 1.0 \\
\hline Total & 100.0 & 100.0 & 100.0 & 100.0 & 100.0 \\
\hline \multicolumn{6}{|c|}{ Characteristics } \\
\hline Phosphorus content [wt $\%$ ] & 0.0 & 1.6 & 4.7 & 7.9 & 7.9 \\
\hline \multicolumn{6}{|l|}{ UL 94 measurement } \\
\hline \multicolumn{6}{|l|}{ Horizontal burning } \\
\hline Flame velocity [mm/min] & $37.2 \pm 2.8$ & $35.0 \pm 1.0$ & extinguish & extinguish & extinguish \\
\hline Dripping & yes & yes & no & no & no \\
\hline \multicolumn{6}{|l|}{ Vertical burning } \\
\hline Dripping & yes & yes & yes & no & no \\
\hline Grade & H-B & H-B & $\mathrm{V}-2$ & $\mathrm{~V}-0$ & $\mathrm{~V}-0$ \\
\hline LOI, (V/V) [\%] & 22 & 22 & 26 & 30 & 29 \\
\hline \multicolumn{6}{|l|}{ Mass loss calorimetric measurement } \\
\hline Time to ignition $\left(t_{i g n}\right)[\mathrm{s}]$ & 70 & 70 & 140 & 695 & 325 \\
\hline Peak of Heat Release Rate $\left(\mathrm{HRR}_{\max }\right)\left[\mathrm{kW} / \mathrm{m}^{2]}\right.$ & 900 & 475 & 275 & 190 & 135 \\
\hline Time to $\mathrm{HRR}_{\max }\left(t_{H R R_{\max }}\right)[\mathrm{s}]$ & 205 & 275 & 730 & 795 & 670 \\
\hline Final residue (res) [wt\%] & 0 & 3 & 13 & 23 & 32 \\
\hline Time to final residue $\left(t_{\text {res }}\right)[\mathrm{s}]$ & 250 & 310 & 860 & 830 & 850 \\
\hline Average Mass Loss Rate $\left(\mathrm{MLR}=60 \cdot(100-\mathrm{res}) / t_{\text {res }}\right)[\mathrm{wt} \% / \mathrm{min}]^{*}$ & 24.0 & 18.8 & 6.1 & 5.6 & 4.8 \\
\hline
\end{tabular}

*Equal to the average slope of the Residual mass vs. Time curve multiplied by $(-1)$ 


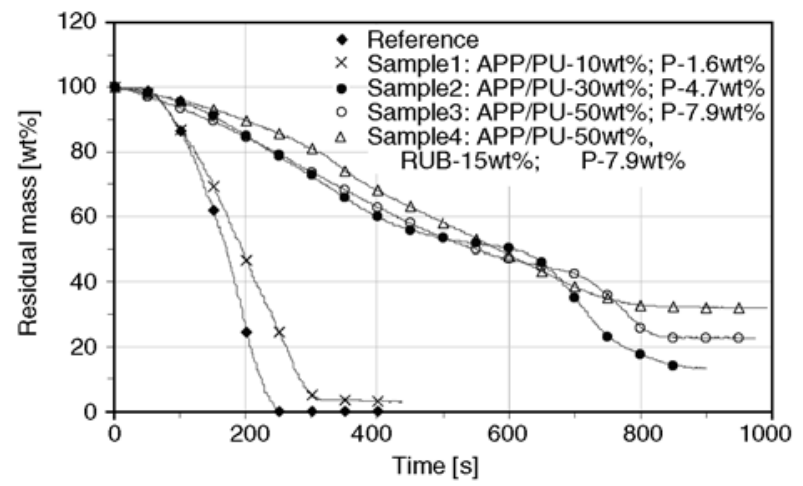

Figure 3. Residual Mass vs. Time in mass loss calorimetric measurement of the compounds

ple 1 was dripping and burnt away completely (see values of res). However the $H R R_{\max }$ dropped by approx. 50\%, the reduction of MLR exceeded $20 \%$ and $t_{H R R \max }$ increased moderately, by $70 \mathrm{~s}$. The flame velocity at horizontal burning reduced moderately, by approx. $6 \%$.

The increase of phosphorus content (Sample 1-3) led to a direct improvement in both UL 94 (up to $\mathrm{V}-0$ grade) and LOI (up to 30). Values of $t_{i g n}$ and res increased tendentiously. At the same time $H R R_{\max }$ and $M L R$ decreased significantly. Comparing to Sample 1, $t_{H R R_{\max }}$ shifted towards the higher ranges, by $455 \mathrm{~s}$ (Sample 2) and $520 \mathrm{~s}$ (Sample 3). This means an extremely extended term available for escape in case of building or vehicle fire where the interior plastic parts are made of these compounds. Expressive drop of $M L R$ values, to approx. a fourth that of Reference could be observed.

The introduction of rubber powder to the compound, containing the APP/PU flame retardant additive system $50.0 \mathrm{wt} \%$ on the expense of LDPE/ EVA matrix (Sample 4) affected the burning properties quite variously compared to the Sample 3, containing the same amount of APP/PU system. The alteration in the LOI value was negligible. The UL 94 grade kept its value. On the other hand the $H R R_{\max }$ decreased by approx. $30 \%$. $H R R_{\max }$ being less than a sixth that of the Reference and $t_{H R R \max }$ being more than 10 minutes, provides increased chance of escape in case of fire. The amount of res increased by $9 \mathrm{wt} \%$, while a $15 \%$ decrease in $M L R$ was realized.

\subsection{Gas emission}

Knowledge about the products of combustion process, mainly about the gases emitted from materials to be applied in the interior of buildings, is important. Even if a material basically is flameretardant under forced burning conditions it will more or less decompose.

The forced burning can be modelled either by oxygen consumption cone [41] or mass loss calorimeter. The evolved gases can be piped in the measuring cell of an FTIR spectrometer and analysed in line throughout the burning process. The scheme of such a construction is demonstrated in Figure 1. The 3D FTIR spectra of the Reference and Sample 1, 3 and 4 can be seen in Figure 4.

The reference and flame retarded samples differ largely, especially in respect of the maximum absorbance in the wavenumber region characteristic for the $\mathrm{CO}_{2}$ and $\mathrm{CO}$ gas components.

The relative amount of the evolved gases was calculated by integration of the 3D FTIR spectra. The integrals for $\mathrm{CO}_{2}$ and $\mathrm{CO}$ and the $\mathrm{CO}_{2} / \mathrm{CO}$ yield ratios are presented in Table 2.

Introduction of $10 \% \mathrm{APP} / \mathrm{PU}$ system reduced the amount of evolved $\mathrm{CO}_{2}$ and $\mathrm{CO}$ by 15 and $19 \%$, respectively (Reference and Sample 1).

The amount of $\mathrm{CO}_{2}$ and $\mathrm{CO}$ decreased with increasing APP/PU content (Sample 1-3). Comparing Sample 1 and 3, a 70 and a 60\% decrease in the amount of $\mathrm{CO}_{2}$ and $\mathrm{CO}$ was realized, respectively. Comparing Sample 2 and 3, the drastic cutback in the amount of $\mathrm{CO}_{2}$ to a value of less than a third resulted in the decrease of $\mathrm{CO}_{2} / \mathrm{CO}$ yield ratio to approx. a half.

Sample 4, prepared by incorporation of rubber powder in the composition Sample 3 on expense of LDPE/EVA, gives an increased amount of both $\mathrm{CO}_{2}$ and $\mathrm{CO}$, compared to the Sample 3. These values, even so, are approx. 50 and $60 \%$ those of Reference, respectively.

Table 2. Relative amount of the evolved $\mathrm{CO}_{2}$ and $\mathrm{CO}$ gases. $\mathrm{CO}_{2} / \mathrm{CO}$ yield ratios for Reference and Sample 1, 2, 3 and 4

\begin{tabular}{|l|c|c|c|c|c|}
\hline \multicolumn{1}{|c|}{ Values evaluated from the FTIR spectra } & Reference & $\mathbf{1}$ & $\mathbf{2}$ & $\mathbf{3}$ & $\mathbf{4}$ \\
\hline Relative amount of evolved $\mathrm{CO}_{2}[-]$ & 12590 & 10762 & 9020 & 2930 & 6707 \\
\hline Relative amount of evolved $\mathrm{CO}[-]$ & 83 & 67 & 39 & 26 & 51 \\
\hline $\mathrm{CO}_{2} / \mathrm{CO}$ yield ratio $[-]$ & 151.7 & 160.6 & 231.3 & 112.7 & 131.5 \\
\hline
\end{tabular}



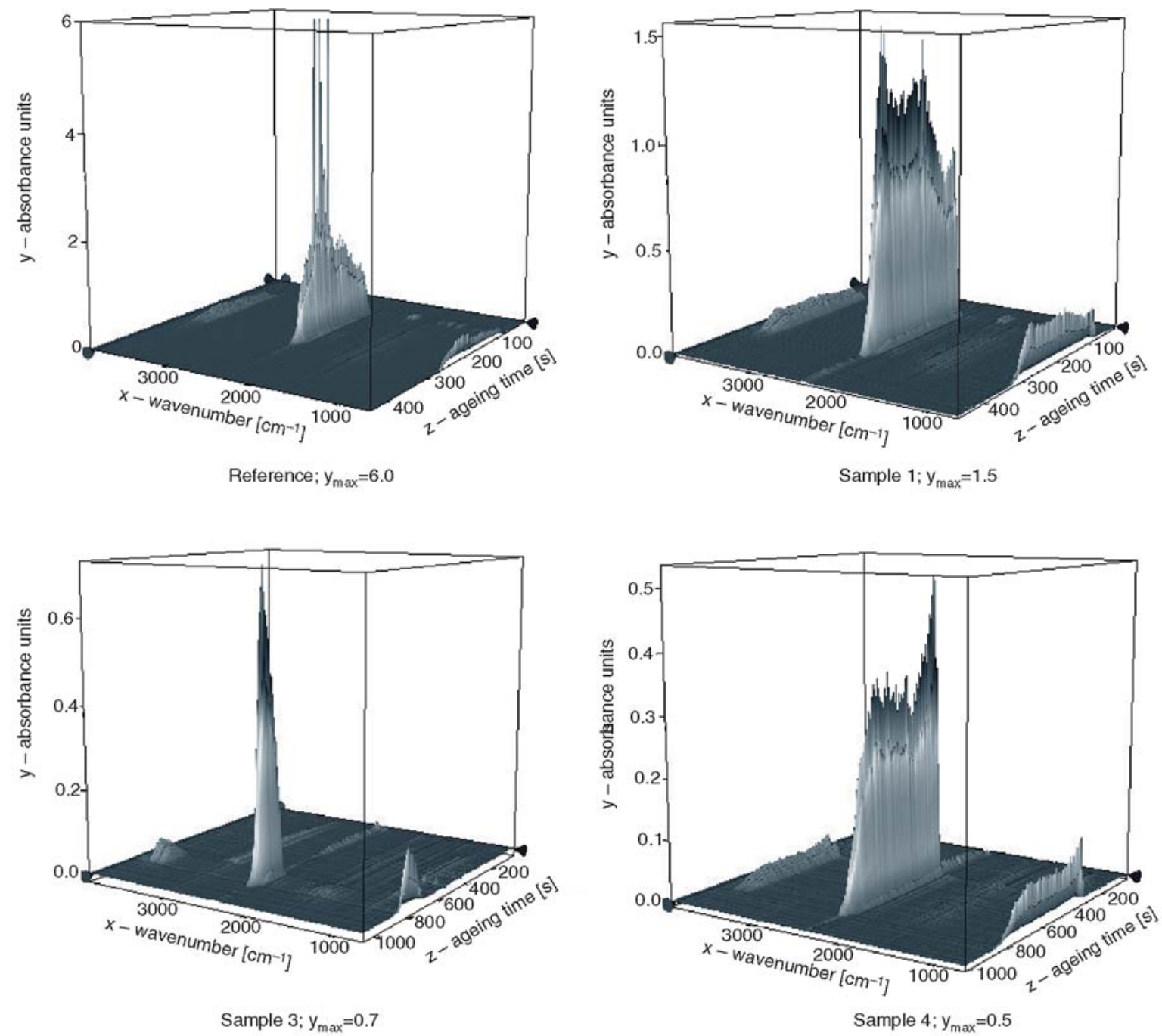

Figure 4. The 3D FTIR spectra of the gases releasing from Reference and Sample 1, 3 and 4, where $y=$ absorbance, $x=$ vawenumber $\left(0-4000 \mathrm{~cm}^{-1}\right), z=$ ageing time $(0-350 \mathrm{~s})$

\subsection{Mechanical properties}

The values of tensile strength, relative elongation at break, tensile modulus and deviations are shown in Table 3.

Both APP/PU and APP/PU/RUB systems reduce the tensile strength of the compounds, as it was expected, proportional to the amount of the additive. The decrease of relative elongation at break of the compounds with increasing amount of additive is more drastic. It has to be remarked that the introduction of RUB prevents the strong reduction of elongation at break. The addition of both APP/PU and APP/PU/RUB systems to the LDPE/EVA matrix led to an increase in stiffness. The higher the APP/PU additive content, the higher the tensile modulus (Sample 1-3). Comparing Samples 1 and 3 , it increased to a value of more than three times. Preserving the content of the APP/PU system the same (50.0 wt \%), addition of rubber powder resulted in a decrease by more than $10 \%$ (Sample 3 and 4). The mechanical properties of the compounds suggest, the APP/PU and APP/PU/RUB

Table 3. Values of tensile strength [MPa], relative elongation [\%], tensile modulus [MPa] and deviations for Reference and Sample 1, 2, 3 and 4

\begin{tabular}{|l|c|c|c|c|c|}
\hline \multicolumn{1}{|c|}{ Tensile properties } & Reference & $\mathbf{1}$ & $\mathbf{2}$ & $\mathbf{3}$ & $\mathbf{4}$ \\
\hline Tensile strength [MPa] & $11.2 \pm 0.6$ & $5.8 \pm 0.4$ & $3.7 \pm 0.2$ & $2.3 \pm 0.1$ & $1.6 \pm 0$ \\
\hline Relative elongation [\%] & $1124 \pm 23$ & $505 \pm 55$ & $185 \pm 27$ & $6 \pm 0$ & $32 \pm 4$ \\
\hline Tensile modulus [MPa] & $24.7 \pm 1.9$ & $27.7 \pm 1.9$ & $58.7 \pm 0.9$ & $82.3 \pm 5.1$ & $70.6 \pm 3.4$ \\
\hline
\end{tabular}


flame retardant compounds can be used in such applications, where not tensile but compression strength is required from the products prepared from the compounds.

\section{Conclusions}

Flame retarded LDPE/EVA based polymeric compounds can be formulated by incorporation of an intumescent flame retardant system, consisting of waste polyurethane and ammonium polyphosphate. This system could be applied for utilization of waste rubber as well. The compound containing $40 \mathrm{wt} \%$ waste polyurethane and rubber powder as a whole, shows fire retardancy, low $H R R_{\max }$ and high of $t_{H R R_{\max }}$, which provides chance of escape in case of fire.

The environmental impact of the compounds was detected by IR analysis of the evolved gases during the mass loss calorimetric measurements. The amount of $\mathrm{CO}_{2}$ and $\mathrm{CO}$ decreased with increasing APP/PU content. The rubber powder containing compound had also a considerably reduced $\mathrm{CO}_{2}$ and $\mathrm{CO}$ emission compared to Reference. The APP/PU and APP/PU/RUB systems reduced the tensile strength proportionally to the additive content. The relative elongation at break decreased by the additives more drastically; however, the RUB additive partly inhibited this effect. The introduction of additives led to an increase in modulus.

The processability of compounds containing recycled materials is excellent and applicable as fire retarded thermoplastic rubbery material for engineering purposes such as floor covering or interior panel in construction of buildings.

\section{Acknowledgements}

This work was supported by the Hungarian Ministry of Education (Multirec Project, GVOP 3.1.1.-2004-05-0531/ 3.0), EU 6 Nanofire project (NMP3-CT 2004-505637) and Hungarian Research Found (OTKA T049121). BUTE Natural- and Sport Scientific Assoc.

\section{References}

[1] Directive 2000/53/EC of the European Parliament and of the Council of 18 September 2000 on end-of life vehicles. Official Journal of the European Communities, L 269, 34-42 (2000).
[2] Zabaniotou A. A., Stavropoulos G.: Pyrolysis of used automobile tires and residual char utilization. Journal of Analytical and Applied Pyrolysis, 70, 711-722 (2003).

[3] Barbooti M. M., Mohamed T. J., Hussain A. A., Abas F. O.: Optimization of pyrolysis conditions of scrap tires under inert gas atmosphere. Journal of Analytical and Applied Pyrolysis, 72, 165-170 (2004).

[4] Wu W., Yoshikawa K.: R \& D on micro-pyrolyzer for solid wastes using high temperature steam and air. JSME International Journal, Series B: Fluids and Thermal Engineering, 45, 487-491 (2002).

[5] Conesa J. A., Martín-Gullón I., Font R., Jauhiainen J.: Complete study of the pyrolysis and gasification of scrap tires in a pilot plant reactor. Environmental Science and Technology, 38, 3189-3194 (2004).

[6] Bébar L., Stehlík P., Havlen L., Oral J.: Analysis of using gasification and incineration for thermal processing of wastes. Applied Thermal Engineering, 25, 1045-1055 (2005).

[7] Rios R. R. V. A., Gontijo M., Ferraz V. P., Lago R. M., Araujo M. H.: Devulcanization of styrenebutadiene (SBR) waste tire by controlled oxidation. Journal of the Brazilian Chemical Society, 17, 603-608 (2006).

[8] Jana G. K., Das C. K.: Devulcanization of natural rubber vulcanizates by mechanochemical process. Polymer-Plastics Technology and Engineering, 44, 13991412 (2005).

[9] Jana G. K., Das C. K.: Recycling natural rubber vulcanizates through mechanochemical devulcanization. Macromolecular Research, 13, 30-38 (2005).

[10] Kojima M., Tosaka M., Ikeda Y.: Chemical recycling of sulfur-cured natural rubber using supercritical carbon dioxide. Green Chemistry, 6, 84-89 (2004).

[11] Kojima M., Tosaka M., Ikeda Y., Kohjiya S.: Devulcanization of carbon black filled natural rubber using supercritical carbon dioxide. Journal of Applied Polymer Science, 95, 137-143 (2005).

[12] Feng W., Isayev A. I.: Recycling of tire-curing bladder by ultrasonic devulcanization. Polymer Engineering and Science, 46, 8-18 (2006).

[13] Ghose S., Isayev A. I.: Ultrasonic devulcanization of unfilled polyurethane rubber using coaxial and grooved barrel reactors: A comparative study. Journal of Polymer Engineering, 25, 331-343 (2005).

[14] Lee D., Kim J. H.: Failure analysis on rubber-modified epoxy resin under various loading speed conditions. Key Engineering Materials, 297-300, 1907 1912 (2005).

[15] Unnikrishnan K. P., Thachil E. T.: Toughening of epoxy resins. Designed Monomers and Polymers, 9, 129-152 (2006).

[16] Kim N. H., Kim H. S.: Interaction of toughening mechanisms in a hybrid epoxy system. Journal of Applied Polymer Science, 100, 4470-4475 (2006). 
[17] Nakason C., Pechurai W., Sahakaro K., Kaesaman A.: Rheological, mechanical and morphological properties of thermoplastic vulcanizates based on NR-gPMMA/PMMA blends. Polymers for Advanced Technologies, 16, 592-599 (2005).

[18] Nakason C., Wannavilai P., Kaesaman A.: Thermoplastic vulcanizates based on epoxidized natural rubber/polypropylene blends: Effect of compatibilizers and reactive blending. Journal of Applied Polymer Science, 100, 4729-4740 (2006).

[19] Nair M. N. R., Nair M. R. G.: Compatibility studies and characterisation of a PVC/NR blend system using NR/PU block copolymer. Polymer Bulletin, 56, 619631 (2006).

[20] Castrovinci A., Camino G., Drevelle C., Duquesne S., Magniez C., Vouters M.: Ammonium polyphosphatealuminum trihydroxide antagonism in fire retarded butadiene-styrene block copolymer. European Polymer Journal, 41, 2023-2033 (2005).

[21] Pal K., Rastogi J. N.: Development of halogen-free flame-retardant thermoplastic elastomer polymer blend. Journal of Applied Polymer Science, 94, 407415 (2004).

[22] Li B., Liu L., Luo H., Luo Y., Jia D.: Studies on flame retadancy of the organoclay/natural rubber nanocomposites (in Chinese). Acta Phytotaxonomica Sinica, 5, 456-461 (2007).

[23] Mishra S., Shimpi N. G.: Effect of the variation in the weight percentage of the loading and the reduction in the nanosizes of $\mathrm{CaSO}_{4}$ on the mechanical and thermal properties of styrene-butadiene rubber. Journal of Applied Polymer Science, 104, 2018-2026 (2007).

[24] Gui H., Zhang X. H., Liu Y. Q., Dong W. F., Wang Q. G., Gao J. M., Song Z. H., Lai J. M., Qiao J. L.: Effect of dispersion of nano-magnesium hydroxide on the flammability of flame retardant ternary composites. Composites Science and Technology, 67, 974-980 (2007).

[25] Gui H., Zhang X. H., Dong W. F., Wang Q. G., Gao J. M., Song Z. H., Lai J. M., Liu Y. Q., Huang F., Qiao J. L.: Flame retardant synergism of rubber and $\mathrm{Mg}(\mathrm{OH})(2)$ in EVA composites. Polymer, 48, 25372541 (2007).

[26] Gui H., Zhang X., Dong F., Gao M., Song Z., Lai J., Liu Y., Huang F., Qiao J., Wang Q.: Effect of rubbers on the flame retardancy of EVA/ultrafine fully vulcanized powdered rubber/nanomagnesium hydroxide ternary composites. Polymer Composites, 28, 479-483 (2007).

[27] Bugajny M., Le Bras M., Bourbigot S., Delobel R.: Thermal behaviour of ethylene-propylene rubber/ polyurethane/ammonium polyphosphate intumescent formulations - a kinetic study. Polymer Degradation and Stability, 64, 157-163 (1999).

[28] Bugajny M., Le Bras M., Bourbigot S., Poutch F., Lefebvre J-M.: Thermoplastic polyurethanes as carbonization agents in intumescent blends. Part 1: Fire retardancy of polypropylene/thermoplastic polyurethane/ammonium polyphosphate blends. Journal of Fire Sciences, 17, 494-513 (1999).
[29] Duquesne S., Le Bras M., Delobel R., Camino G., Gengembre L.: X-ray photoelectron spectroscopy study of the ammonium polyphosphate-polyurethane system used as fire-retardant additive in EVA. Journal of Fire Sciences, 21, 89-115 (2003).

[30] Bourbigot S., Le Bras M., Duquesne S., Rochery M.: Recent advances for intumescent polymers. Macromolecular Materials and Engineering, 289, 499-511 (2004).

[31] Bugajny M., Le Bras M., Bourbigot S.: Thermoplastic polyurethanes as carbonization agents in intumescent blends. Part 2: Thermal behavior of polypropylene/ thermoplastic polyurethane/ammonium polyphosphate blends. Journal of Fire Sciences, 18, 7-27 (2000).

[32] Hull T. R., Wills C. L., Artingstall T., Price D., Milnes G. J.: Mechanism of smoke and CO suppression from EVA composites. in 'Fire Retardancy of Polymers New Applications of Mineral Fillers' (eds.: Le Bras M., Wilkie C. A., Bourbigot S., Duquesne S., Jama C.) The Royal Society of Chemistry, Cambridge, 372-385 (2005).

[33] Wills C. L., Arotsky J., Hull T. R., Price D., Purser D. A., Purser J.: Products of incomplete combustion from fire studies in the Purser furnace. in 'Fire Retardancy of Polymers - New Applications of Mineral Fillers' (eds.: Le Bras M., Wilkie C. A., Bourbigot S., Duquesne S., Jama C.) The Royal Society of Chemistry, Cambridge, 386-398 (2005).

[34] Balikó L., Veres G., Vékony S.: Method of selective recovering components from multi-component elastic waste material and apparatus for producing fine-grained rubber powder. WO/2001/053053, Hungary (2001).

[35] UL 94: Tests for flammability of plastic materials for parts in devices and appliances (1996).

[36] ASTM D 2863-06a: Standard test method for measuring the minimum oxygen concentration to support candle-like combustion of plastics (Oxygen Index) (1996).

[37] ISO 13927: Plastics. Simple heat release test using a conical radiant heater and a thermopile detector (2001).

[38] Babrauskas V.: Development of the cone calorimeter. A bench-scale heat release rate apparatus based on oxygen consumption. Fire and Materials, 8, 81-95 (1984).

[39] Socrates G.: Infrared and Raman characteristic group frequencies: Tables and charts. Wiley and Sons, New York (2004).

[40] ISO 527-2: Plastics. Determination of tensile properties. Part 2: Test conditions for moulding and extrusion plastics (1993).

[41] Zhang F., Zhang J., Wang Y.: Modeling study on the combustion of intumescent fire-retardant polypropylene. Express Polymer Letters, 1, 157-165 (2007). 